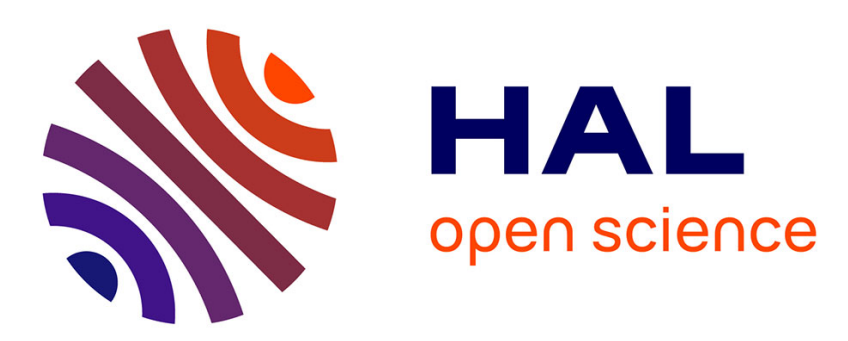

\title{
Influence of conduction electrons in a heavily-doped magnetic semiconductor : a 15Eu Mössbauer study of europium hexaboride
}

J. M. D. Coey, Olivier Massenet, M. Kasaya, Jean Etourneau

\section{To cite this version:}

J. M. D. Coey, Olivier Massenet, M. Kasaya, Jean Etourneau. Influence of conduction electrons in a heavily-doped magnetic semiconductor : a 15Eu Mössbauer study of europium hexaboride. Journal de Physique Colloques, 1979, 40 (C2), pp.C2-333-C2-336. 10.1051/jphyscol:19792118 . jpa-00218488

\section{HAL Id: jpa-00218488 https://hal.science/jpa-00218488}

Submitted on 1 Jan 1979

HAL is a multi-disciplinary open access archive for the deposit and dissemination of scientific research documents, whether they are published or not. The documents may come from teaching and research institutions in France or abroad, or from public or private research centers.
L'archive ouverte pluridisciplinaire HAL, est destinée au dépôt et à la diffusion de documents scientifiques de niveau recherche, publiés ou non, émanant des établissements d'enseignement et de recherche français ou étrangers, des laboratoires publics ou privés. 


\title{
INFLUENCE OF CONDUCTION ELECTRONS IN A HEAVILY-DOPED MAGNETIC SEMICONDUCTOR : A $15 I E \cup$ MÖSSBAUER STUDY OF EUROPIUM HEXABORIDE
}

\author{
J.M.D. Coey, O. Massenet, M. Kasaya ${ }^{\mathbf{X}+}$ and J. Etourneau* \\ Groupe des Transitions de Phases, C.N.R.S., B.P. 166, 38042 Grenoble Cedex, France \\ Laboratoire de Chimie du Solide du C.N.R.S., Université de Bordeaux I, 33405 Talence, Fronce
}

\begin{abstract}
Rêsumé.- Dans cinq échantillons diffêrents d'hexaboride d'europium, EuB 6 , on a observé que 1'europium était divalent et aucune évidence de valence intermédiaire n'a étē observêe. L'ordre magnétique évolue depuis l'ordre ferromagnétique dans le matériau presque stoechiométrique à l'ordre antiferromagnétique dans $E_{u B s},{ }_{8} \mathrm{C}_{0}, 2$ passant par une région intermédiaire mictomagnétique avec un échange inhomogène autour de $E_{u B},{ }_{9} C_{0}, 1$. On suggère que des amas ferromagnétiques d'europium autour des atomes de carbone donneurs sont couplés antiferromagnétiquement à ceux entourant un carbone adjacent par échange direct électronique.
\end{abstract}

\begin{abstract}
The europium is divalent and no evidence of mixed valence is found in any of five different samples of europium hexaboride. The magnetic order evolves from ferromagnetic in near-stoichiometric material to antiferromagnetic in EuB ${ }_{5},{ }_{8} \mathrm{C}_{0}, 2$ passing through a mictomagnetic region with inhomogeneous exchange around $\mathrm{EuB}_{5}, \mathrm{C}_{0}, 1$. There $1 \mathrm{t}$ is suggested that ferromagnetic europiun clusters around the carbon donors are coupled antiferromagnetically by direct exchange of electrons from adjacent donors.
\end{abstract}

The magnetic properties of europium hexaboride are the subject of some controversy. In the original work, Geballe et al reported $E_{u} B_{6}$ as a ferromagnetic semiconductor with $T_{c}=8.5 \mathrm{~K} / 1 /$. Subsequent measurements on other polycrystalline samples yielded values in the range $8-15 \mathrm{~K}$. The first single crystal /2/ however did not order ferromagnetically despite a positive paramagnetic Curie temperature, $\theta_{p}=9 \mathrm{~K} \mathrm{/3/.} \mathrm{Isikawa} \mathrm{et} \mathrm{al} \mathrm{interpreted} \mathrm{their} \mathrm{data}$ as showing that the crystal was antiferromagnetic and suggested that this is the intrinsic behaviour of the compound $/ 2 /$. Very recently, Kasaya et al have studied crystals and powders of $E_{4 B_{6-x}} C_{x}$ with controlled carbon content, $0<x<0.21 / 4 /$. Carbon acts an electron donor in the $B_{6}$ framework, so $x$ is approximately the conduction electron content. $\theta_{p}$ was found to decrease regularly from $+15 \mathrm{~K}$ to $-7 \mathrm{~K}$ with increasing $x$, crossing zero at $x=0.13$. It appears that conduction electrons contribute an antiferromagnetic exchange interaction. At the same time there is a small decrease in lattice parameter from 4.1855 for undoped samples to $4.1695 \AA$ for $x: 0.21$

In this paper, we report ${ }^{151} \mathrm{Eu}$ Mössbauer data on five samples of europium hexaboride produced in different ways, including two intentionally doped with carbon. We were particularly interested

tPermanent address : Department of Physics,Tohoku University, Sendai 980, Japan. to find out if samples with $\theta_{p} \sim 0$ were magnetically ordered, and whether the exchange interactions in doped samples were spatially homogeneous.

Details of the samples appear in the table. It will be convenient to take the lattice constant $a_{0}$ as the characteristic parameter of each sample as the work of Kasaya et al suggests that $a_{0}$ decreases uniformly with increasing conduction electron content, n. Although carbon was not determined in sample III, comparison with the data in reference 4 suggests $x \sim 0.05$.

Mössbauer spectra were obtained on absorbers with $25 \mathrm{mg} / \mathrm{cm}^{2}$ of each sample at $296 \mathrm{~K}$ and at several temperatures in the range $1.6-20 \mathrm{k}$. At room-temperatures a single 1 ine with a typically divalent isomer shift, $-12.7(.1) \mathrm{m} / \mathrm{s}$ relative to the source ${ }^{151} \mathrm{Sm}$ in $\mathrm{SmF}_{3}$, was observed in all five samples. No sign of a $\mathrm{Eu}^{3+} \mathrm{line}$ was seen at any temperature, so a limit of $3 \%$ is thereby set on any possible inhomogeneous valence mixture. Nor is there any significant variation of the isomer shift between 20 and $296 \mathrm{~K}(<0.2 \mathrm{~mm} / \mathrm{s})$, a result which places a limit of $2 \%$ on any change in homogeneous valence admixture with temperature. These results were confirmed by measurements of the susceptibility which gave a temperature-independent Curie constant of $7.7(2)$ at temperatures up to $800 \mathrm{~K}$, as expected for $\mathrm{Eu}^{2+}$. It follows that the gap between the $4 f$ level and the conduction band in $\operatorname{EuB}_{6}$ is at 


\begin{tabular}{|c|c|c|c|c|c|c|c|c|}
\hline Sample lto & Description & $\begin{array}{c}\text { Lattice Parameter } \\
a_{0}(\AA)\end{array}$ & $\begin{array}{c}\text { Carriers/Eu } \\
n\end{array}$ & $\begin{array}{l}\text { Ordering Temperature } \\
\qquad \tau_{c}(x)\end{array}$ & $\begin{array}{c}H_{h f}(1.6) \\
(k \circ e)\end{array}$ & $\begin{array}{c}\ln f(4.2) \\
(k D e)\end{array}$ & $\underset{h H_{h f}(4,2)}{(k D e)}$ & Reference \\
\hline$I$ & Stoichionetric powder & $4.1855(3)$ & 20 & $12.5(.5)$ & 332 & 308 & 20 & 4 \\
\hline II & $\begin{array}{l}\text { I, heated in Eu } \\
\text { vapour }\end{array}$ & $4.1855(3)$ & 20 & $10.7(.5)$ & 336 & 277 & $\approx 0$ & - \\
\hline III & Single crystal & $4.1810(3)$ & 0.03 & $6.3(.3)$ & 316 & 262 & 40 & 2 \\
\hline IV & $\begin{array}{l}\text { Carbon-doped powder } \\
x=0.14\end{array}$ & $4.2733(3)$ & $0.14^{+}$ & $7(1)$ & nd & 270 & 25 & 4 \\
\hline$v$ & $\begin{array}{l}\text { Carbon-doned Dowder } \\
x=0.21\end{array}$ & $4.1695(3)$ & $0.21^{+}$ & $5.5(.5)$ & 313 & 274 & 20 & - \\
\hline
\end{tabular}

Assumed equal to $x$ in the formula EuB $6-x C_{x}$

Table I : Details of the europium hexaboride samples.

least $0.2 \mathrm{eV}$, in accord with resistivity measurements at high temperatures which yielded an activation energy of $0.3 \mathrm{eV} / 5 /$.

The appearance of magnetic hyperfine splitting indicates that all our samples are magnetically ordered at $4.2 \mathrm{~K}$, regardless of the value of $\theta_{p}$. Three typical spectra are shown in figure 1.

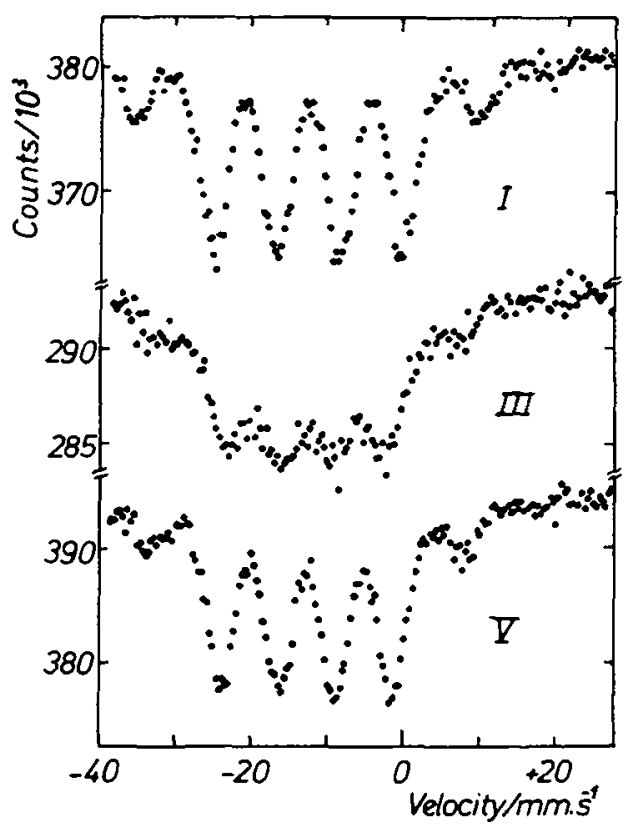

Fig. 1 : Mössbauer spectra at $4.2 \mathrm{~K}$ of ferromagnetic (I), mictomagnetic (III) and antiferromagnetic (V) samples of europium hexaboride. Particulars of each sample are given in the table.

Both the nominally stoichiometric samples ( $I$ and II) and the most carbon rich one (V) show unbroadened lines in the magnetic spectra, but the lines of samples with intermediate lattice parameters (III and IV) are greatly broadened. The corresponding spread in hyperfine field $\Delta \mathrm{H}_{\mathrm{hf}}$ is given in the table. Line broadening in sample III cannot be due to macroscopic inhomogeneity because identical spectra were obtained for samples from different parts of the crystal. Nor is it related to the proximity of the ordering temperature (by poor temperature control or homogeneity) because it is absent in $V$, whose ordering temperature is just as low as that of III or IV. The broadening disappears in spectra taken at $1.6 \mathrm{~K}$, so it must be associated with inhomogeneity of the exchange interactions on a microscopic scale. The breadth of the exchange distribution can be estimated from local molecular field theory /6/ to be roughly as great as its average value. The absence of any significant broadening in samples $I, I I$ and $V$ shows that the exchange interactions there are essentially homogeneous.

Magnetic ordering temperatures were derived for all five samples by extrapolating the hyperfine field to zero. For the ferromagnets, I and II, these temperatures agree fairly well with those obtained from Arrott plots /7/. For the other samples they correspond to a cusp in the susceptibility /7/. V appears to be antiferromagnetic, from the consistency between $\theta_{p}, T_{c}$ and $x\left(T_{c}\right)$. III and IV however may best be described as mictomagnets since they contain a spatially inhomogeneous distribution of exchange interactions of both signs. The susceptibility cusp in these two samples is eliminated in fields of $2-3 \mathrm{kOe}$ whereas that of sample $\mathrm{V}$ persists in fields greater than $10 \mathrm{kOe}$. Figure 2 shows the magnetic phase diagram of the europium hexaboride system as a function of lattice parameter. The second scale relates $a_{0}$ to the 
approximate conduction electron concentration using the results in reference $/ 4 /$.

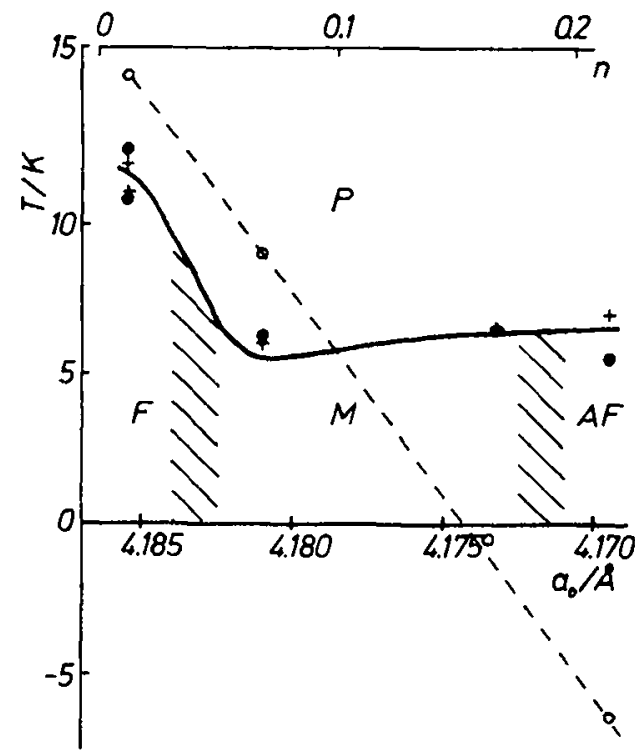

Fig. 2 : Magnetic phase diagram of europium hexaboride showing paramagnetic (P), ferromagnetic (F), mictomagnetic (M) and antiferromagnetic (AF) regions. The ordering temperatures and + are derived respectively from Mössbauer and magnetic /7/ data. 0 indicates the paramagnetic Curie temperatures $/ 4 /$.

The small difference ( $\sim 20 \mathrm{kOe}$ ) between the hyperfine fields, extrapolated to $T=0$, in ferromagnetic samples represents the sum of the contribution of the conduction electron spin polarisation to the latter and the supertransferred hyperfine interaction.

While the basic ferromagnetic exchange coupling in near-stoichiometric $E_{4 B_{6}}$ can be understood in terms of the mechanism proposed for Euo $/ 8 /$, it is puzzling that the addition of conduction electrons can give an antiferromagnetic contribution. The RKKY interaction is positive at short distances and low conduction electron densities. The first negative region occurs between $4.5 \times 10^{21}$ and $2.6 \times$ $10^{22}$ per cc at the nearest neighbour distance of EuB $_{6}$. It is impossible to obtain antiferromagnetic nearest-neighbour coupling at concentrations of order 0.05 electrons/Eu $\left(6.8 \times 10^{20}\right.$ per $\left.\mathrm{cc}\right)$ even taking account of the fact that the electron density is not uniformly distributed, but peaked near the donor sites. In the most favourable case, assuming hydrogenic wave functions and a dielectric constant $\varepsilon \sim 4$, the electron density at europium sites adjacent to a carbon impurity is only $2.0 \times 10^{21}$.
The antiferromagnetic coupling must therefore take place at much longer distances. Figure 3 shows how it may come about. There is a high density of states in the impurity band close to a carbon donor and the added electron there couples ferromagnetically to the surrounding group of europium ions.

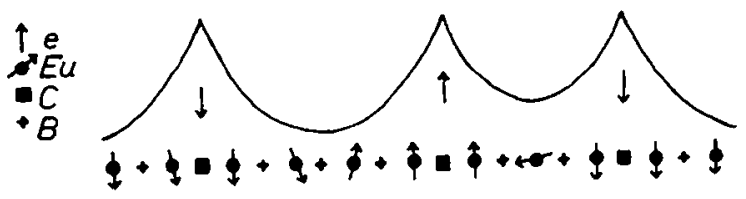

Fig 3 : Schematic representation of mictomagnetic EuB $_{6}$. Ferromagnetic clusters formed around the donor centres are coupled antiferromagnetically by direct exchange between electrons from adjacent donors.

Mid-way between the donors however the electron density is much lower and direct overlap of their hydrogenic wave functions gives antiferromagnetic coupling between the electrons from adjacent donors. In this way, the inhomogeneous exchange in the mictomagnetic region of $E_{u B_{6-x}} C_{x}$ finds a natural explanation. At higher electron concentrations the density in the impurity band becomes uniform and the exchange homogeneous.

Finally we note that there are some signs of competing exchange interactions in nominally stoichiometric, ferromagnetic $\mathrm{EuB}_{6}$. The rise in the magnetization and hyperfine field below the Curie point is much less abrupt than that fiven by the Brillouin function. Also the specific heat anomaly is broad and complex $/ 1,9 /$. These effects probably stem from the presence of some $10^{19}$ carriers, even in the best materials prepared so far. If these carriers turn out to be extrinsic, due to defects or impurities such as trivalent rare earths, then $\mathrm{EuB}_{6}$, with its simple structure and almost rigid Boron lattice, should be an ideal compound for studying the influence of conduction electrons on the magnetism and transport properties for a magnetic semiconductor.

We are grateful to N.V. Dang for performing some of the magnetization measurements and to $\mathrm{J}$. Chappert for the Mössbauer data at $1.6 \mathrm{k}$. The authors have also benefitted from a discussion with Professor N.F. Mott. 


\section{References}

/1/ Geballe,T.M., Matthias, B.T., Andres, K., Maita,J.P. Cooper, A.S. and Corenzwit, E., Science 160 (1968) 1443.

/2/ Isikawa, Y., Bajaj, M.M., Kasaya, M., Tanaka, T. and Bannai, E., Sold State Comm. 22 (1977) 573.

/3/ Kasaya, M. and Isikawa, Y., Proc. U.S.-Japan Seminar on Magnetic Semiconductors (unpublished).

/4/ Kasaya, M., Tarascon, J.M., Etourneau, J. and Hagenmul1er, P., Mat. Res. Bull. (1978).

/5/ Mercurio, J.P., Etourneau, J., Naslain, R., Hagemuller, P., and Goodenough, J.M., Solid State Chem. $\underline{9}$ (1974) 37.

16/ Coey, J.M.D. and Sawatzky, G.A., Phys. Stat. Sol. b 44 (1971) 673 .

/7/ Kasaya, M. et al, J. Physique C (1978).

/8/ Kasuya, T., IBM J. Res. Dev. 14 (1970) 214.

/9/ Von Molnar, S., Private Communication. 